\title{
An Unusually Severe Case of Dermatosis Neglecta: A Diagnostic Challenge
}

\author{
Irma Margarita Pérez-Rodríguez Fania Zamantta Muñoz-Garza \\ Jorge Ocampo-Candiani \\ Department of Dermatology, Hospital Universitario Dr. José Eleuterio González, \\ Universidad Autónoma de Nuevo León, Monterrey, Mexico
}

\section{Key Words}

Dermatosis neglecta $\cdot$ Diagnostic challenge

\begin{abstract}
Dermatosis neglecta is a condition secondary to lack of cleanliness, characterized by the formation of hyperkeratotic plaques located in a particular region of the body, usually due to a disability, and it is considered a diagnostic challenge because it can mimic other entities. We present the case of an 18-year-old woman with a 2-month history of progressive brown verrucous plaque in her face. Our first impression was seborrheic dermatitis and she was treated with facial cleanser soap and topic hydrocortisone $1 \%$. One month later, she arrived with new lesions. Because of this our diagnosis changed to Darier's disease versus seborrheic pemphigus versus foliaceus pemphigus. Histopathology and immunofluorescence studies were compatible with seborrheic dermatitis. The patient complained of depression and social withdrawal and denied facial cleansing. Facial cleansing was performed during consultation presenting resolution of the lesions, which confirmed the diagnosis of dermatosis neglecta. Dermatosis neglecta is a disease that can be frequently misdiagnosed, since it has many differential diagnoses, such as hyperkeratotic syndromes. It should be recognized early and aggressive diagnostic and therapeutic methods should be avoided.

(C) 2014 S. Karger AG, Basel
\end{abstract}

\section{Introduction}

Dermatosis neglecta is a condition secondary to lack of cleanliness, characterized by the formation of hyperkeratotic plaques located in a specific region of the body, usually due to a psychiatric condition, physical disability or neurological deficit. It is considered a diagnostic

Irma Margarita Pérez-Rodríguez

Department of Dermatology, Hospital Universitario Dr. José E. Gonzalez

Universidad Autónoma de Nuevo León

Avenida Madero y Gonzalitos s/n, Colonia Mitras Centro

Monterrey, Nuevo León 64460 (Mexico)

E-Mail dra.irma.perez@gmail.com 
Pérez-Rodríguez et al.: An Unusually Severe Case of Dermatosis Neglecta: A Diagnostic Challenge

challenge [1] because it can mimic other entities such as hyperkeratotic syndromes or hyperchromic lesions [2]. We present a patient in whom it was difficult to establish the diagnosis.

\section{Case Presentation}

An 18-year-old woman presented with a 2-month history of progressive brown verrucous plaque on the face, previously treated with no improvement (fig. 1). Our first impression was seborrheic dermatitis and we treated her with facial cleanser soap, topical hydrocortisone $1 \%$ b.i.d. per 3 days and then q.d. per 3 days. One month later she arrived with new lesions, therefore our diagnosis changed to Darier's disease versus seborrheic pemphigus versus foliaceus pemphigus. Biopsy with histopathological and immunofluorescence studies were ordered with results being compatible with seborrheic dermatitis.

We performed a new patient interview and discovered depression secondary to her pathology as well as social withdrawal. In addition, she reported not following instructions and denied any facial cleansing. We performed face cleaning during the consultation. The lesions disappeared and this confirmed the diagnosis of dermatosis neglecta (fig. 2).

\section{Discussion}

Dermatitis neglecta or unwashed dermatosis was first described in 1995 by Poskitt et al. [3] as a condition secondary to the accumulation of sebum, sweat, corneocytes and bacteria forming a hyperkeratotic plaque [4]; later, in 1999, Ruiz-Maldonado et al. [5] changed the name to dermatosis neglecta due to the lack of inflammation.

Dermatosis neglecta is sometimes underdiagnosed because it is asymptomatic [2]. If affects all age groups and both sexes and clinically presents as hyperkeratotic plaques with cornflake-like scales with an evolution of 2-4 months; the lesions disappear with proper washing of the affected area [6,7]. The diagnosis is clinical and lesions can be identified by removing the crusts with isopropyl alcohol [1]. A biopsy is usually not necessary and orthokeratotic hyperkeratosis, papillomatosis and mild acanthosis can be seen without an inflammatory infiltrate $[8,9]$.

The main differential diagnoses are terra firma-forme dermatosis, confluent reticulated papillomatosis of Gourgeot and Carteaud, acanthosis nigricans, verrucous nevi, vagabond's disease, and genetic disorders such as Darier's disease and X-linked ichthyosis [1, 8]. Terra firma-forme dermatosis is clinically very similar to dermatosis neglecta, but unlike dermatosis neglecta, it has a history of good hygiene and responds only to cleaning with isopropyl alcohol $70 \%[2,6,8]$. Dermatitis artefacta presents as self-inflicted injuries or injuries worsened by the patient, while dermatosis neglecta is an act of omission of cleaning by the patient either intentionally or unconsciously [8]. A diagnostic algorithm can be used as a tool when confronted with a difficult pathology [10] (fig. 3). Treatment is based on reinforcing hygiene measures and using keratolytic agents such as urea, retinoic acid, glycolic acid, lactic acid or salicylic acid $[1,7,11]$. 
Pérez-Rodríguez et al.: An Unusually Severe Case of Dermatosis Neglecta: A Diagnostic Challenge

\section{Conclusion}

Dermatosis neglecta is a disease that can be frequently misdiagnosed, since it has many differential diagnoses which include hyperkeratotic syndromes. It should be recognized early to avoid aggressive diagnostic and therapeutic procedures.

\section{Disclosure Statement}

The authors have no conflict of interest to declare. There were no funding sources.

\section{References}

1 Lucas JL, Brodell RT, Feldman SR: Dermatosis neglecta: a series of case reports and review of other dirty-appearing dermatoses. Dermatol Online J 2006;12:5.

2 Choudhary SV, Bisati S, Koley S: Dermatitis neglecta. Indian J Dermatol Venereol Leprol 2011;77:62-63.

3 Poskitt L, Wayte J, Wojnarowska F, Wilkinson JD: 'Dermatitis neglecta': unwashed dermatosis. Br J Dermatol 1995;132:827-829.

4 Pineda-Pineda JA, Pérez-Elizondo AD: Dermatosis neglecta: simulación, una realidad. A propósito de un caso. Rev Argent Dermatol 2012;93. http://www.scielo.org.ar/scielo.php?script=sci_arttext\&pid= S1851-300X2012000300002.

5 Ruiz-Maldonado R, Durán-McKinster C, Tamayo-Sánchez L, Orozco-Covarrubias M: Dermatosis neglecta: dirt crusts simulating verrucous nevi. Arch Dermatol 1999;135:728-729.

-6 Gómez-Fernández C, Casado Verrier B, Sanz Canalejas L, Moreno Alonso de Celada R, Herranz Pinto P: Cornflake-like scales on the ankles and feet. Cleve Clin J Med 2010;77:848-849.

7 Qadir SN, Ejaz A, Raza N: Dermatosis neglecta in a case of multiple fractures, shoulder dislocation and radial nerve palsy in a 35-year-old man: a case report. J Med Case Rep 2008;2:347.

-8 Erker E, Sezer E: Dermatosis neglecta presenting as a brown verrucous plaster. Acta Dermatovenerol Croat 2012;20:123-125.

-9 Richter LL, Miller RM, Hillman JD, Chiu MW: Bilateral thick crusts on the legs. Int J Dermatol 2013;52: 133-135.

10 Tan C: Dirt-adherent dermatosis: not worth an additional name. Arch Dermatol 2010;146:679-680.

-11 Martín-Gorgojo A, Alonso-Usero V, Gavrilova M, Jordá-Cuevas E: Dermatosis neglecta or terra firma-forme dermatosis. Actas Dermosifiliogr 2012;103:932-934. 
Case Reports in
Dermatology

Case Rep Dermatol 2014;6:194-199

DOI: $10.1159 / 000366515$

2014 S. Karger AG, Basel

Pérez-Rodríguez et al.: An Unusually Severe Case of Dermatosis Neglecta: A Diagnostic Challenge

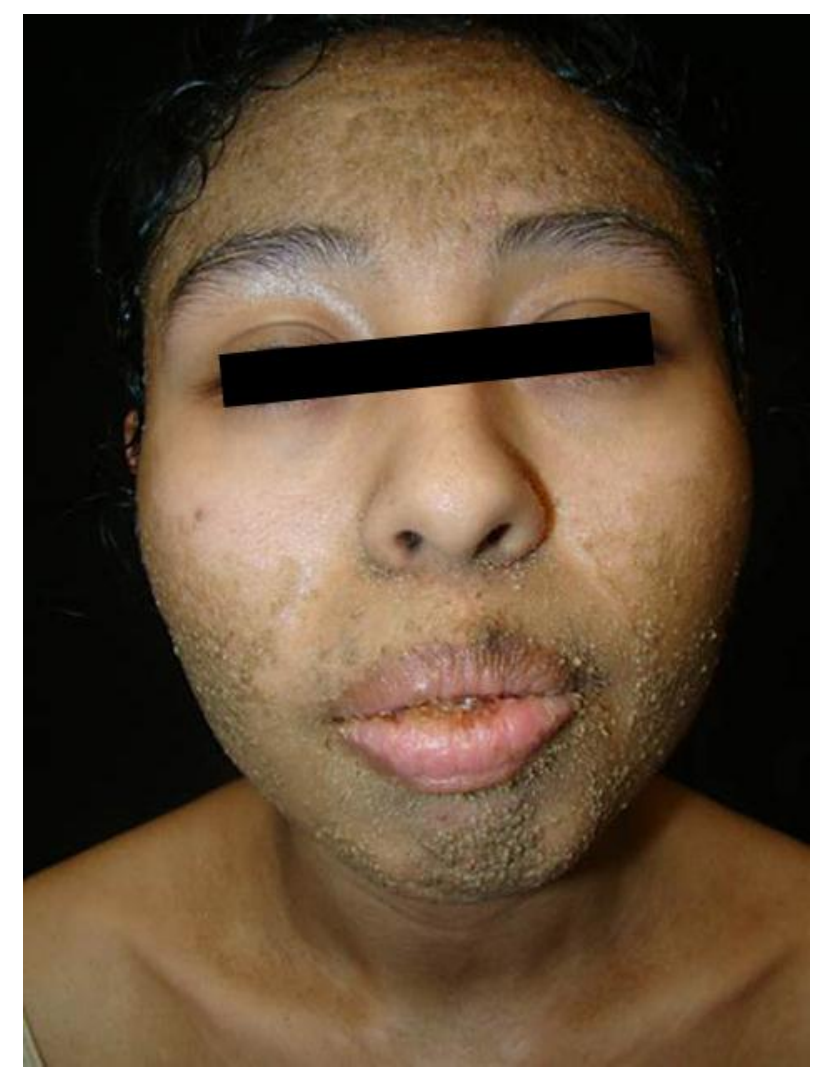

Fig. 1. Patient at first visit. 
Case Reports in
Dermatology

Case Rep Dermatol 2014;6:194-199

DOI: $10.1159 / 000366515$

2014 S. Karger AG, Basel

Pérez-Rodríguez et al:: An Unusually Severe Case of Dermatosis Neglecta: A Diagnostic Challenge

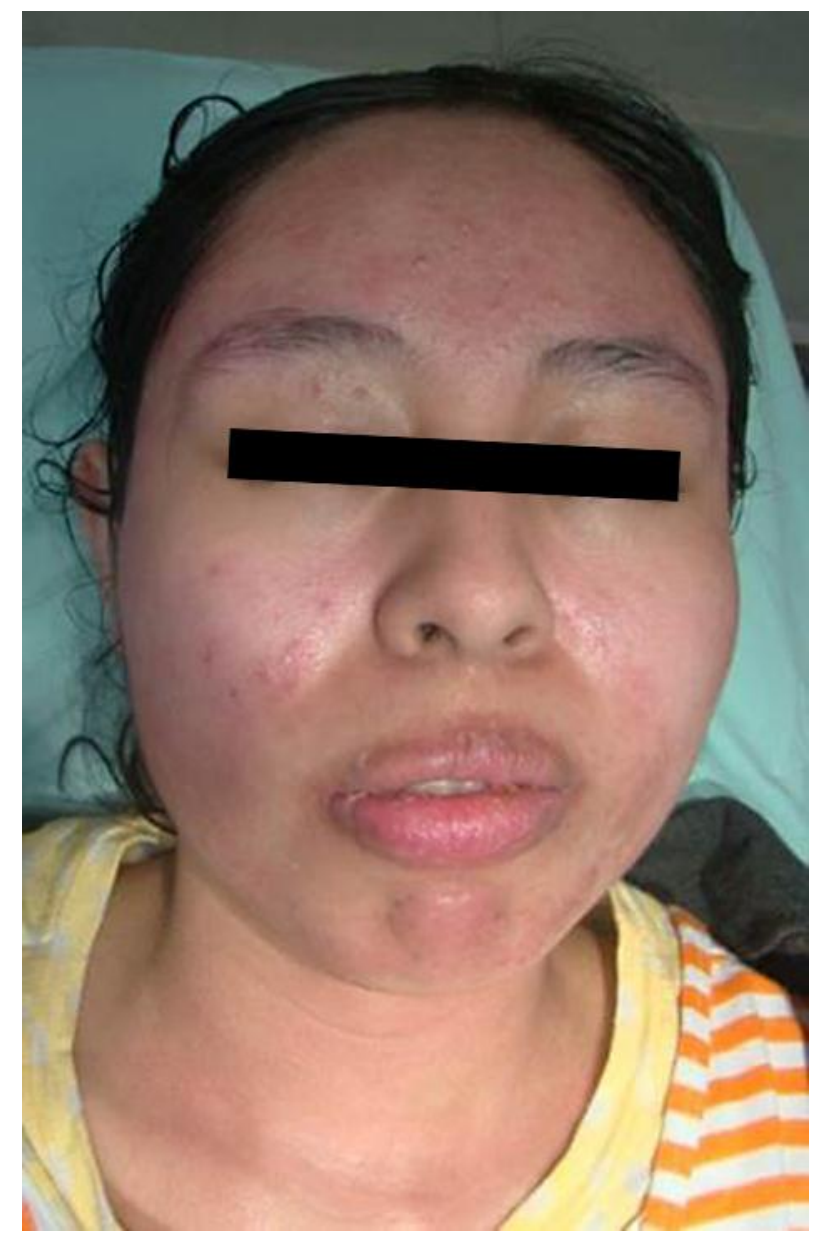

Fig. 2. Patient after facial cleansing. 
Pérez-Rodríguez et al:: An Unusually Severe Case of Dermatosis Neglecta: A Diagnostic Challenge

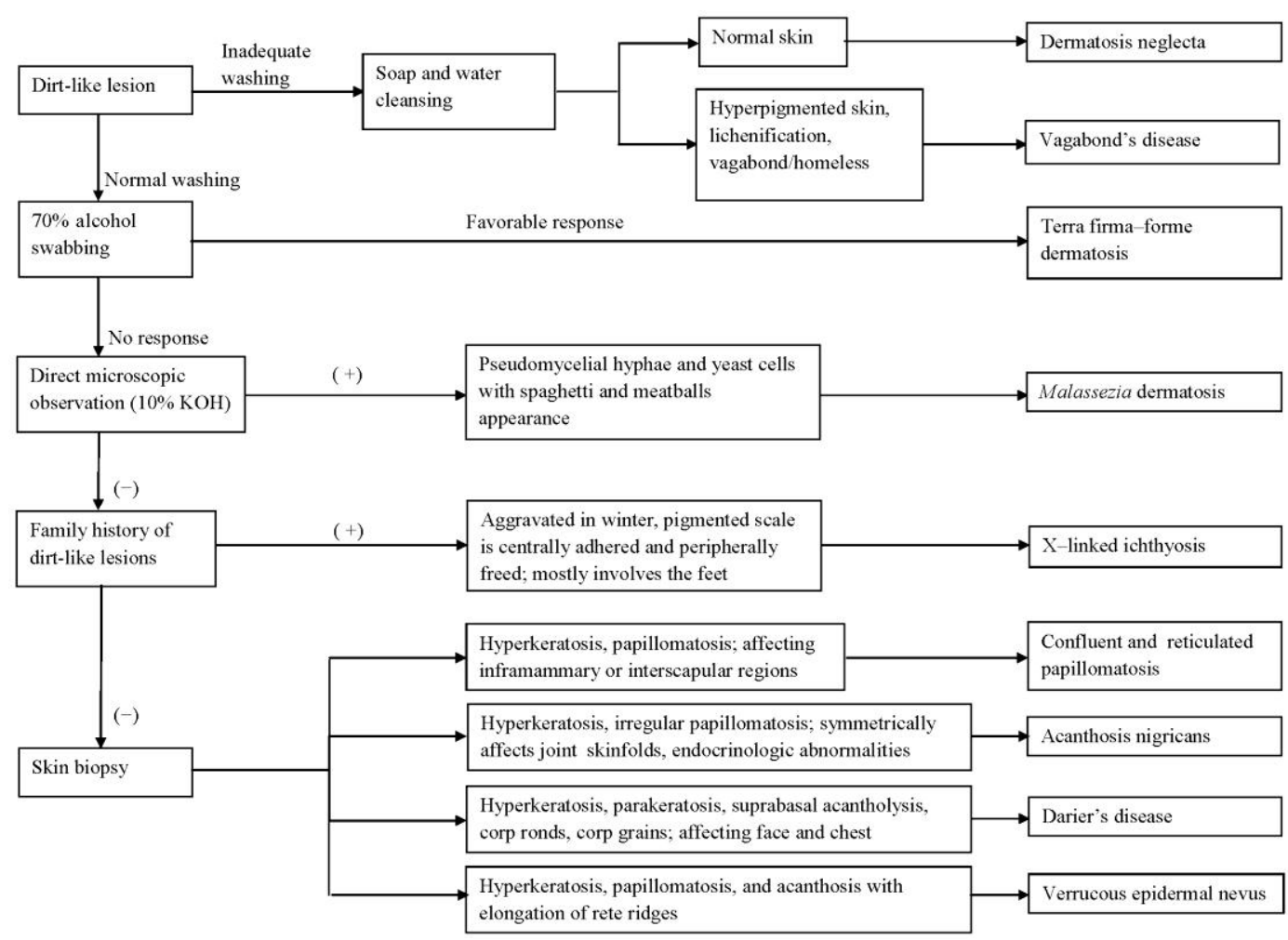

Fig. 3. Algorithm for dirt-like lesions characterized by a pigmented and dirty appearance (based on [10]). 